\title{
Toric intraocular lens orientation and residual refractive astigmatism: an analysis
}

\section{Rick Potvin' \\ Brent A Kramer ${ }^{2}$ \\ David R Hardten ${ }^{3}$ \\ John P Berdahl ${ }^{4}$}

'Science in Vision, Akron, NY, ${ }^{2}$ University of lowa Carver College of Medicine, lowa City, IA, ${ }^{3}$ Minnesota Eye Consultants, Minnetonka, MN, ${ }^{4}$ Vance Thompson Vision, Sioux Falls, SD, USA

Video abstract

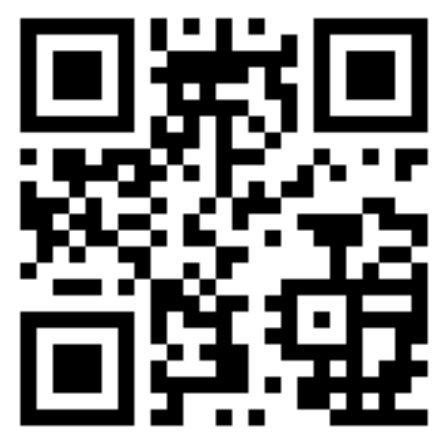

Point your SmartPhone at the code above. If you have a QR code reader the video abstract will appear. Or use: http://youtu.be/taCEJaolttFk

Correspondence: Rick Potvin Science in Vision, 6197 Dye Rd Akron, NY 14001, USA

Tel +I 4076976008

Fax + I 716 4425110

Email rick@scienceinvision.com
This article was published in the following Dove Press journal:

Clinical Ophthalmology

20 September 2016

Number of times this article has been viewed

Purpose: To analyze intraocular lens (IOL) orientation data from an online toric back-calculator (astigmatismfix.com) for determining if differences were apparent by lens type.

Methods: A retrospective review of astigmatismfix.com toric back-calculations that included IOL identification and intended orientation axis.

Results: Of 12,812 total validated calculation records, 8,229 included intended orientation and lens identification data. Of the latter, 5,674 calculations (69\%) involved lenses oriented $5^{\circ}$ or more from their intended position. Using estimated toric lens usage data, the percentage of lenses with orientation $\geq 5^{\circ}$ from intended was $0.89 \%$ overall, but the percentage varied significantly between specific toric lens brands $(P<0.05)$. The percentage of back-calculations related to lenses that were not oriented as intended was also statistically significantly different by lens brand $(P<0.05)$. When IOLs were misoriented, they were significantly more likely to be misoriented in a counterclockwise direction $(P<0.05)$. This was found to be due to a bias toward counterclockwise orientation observed with one specific brand, a bias that was not observed with the other three brands analyzed here.

Conclusion: The percentage of eyes with lens orientation $\geq 5^{\circ}$ from intended in the Toric Results Analyzer data set was $<1 \%$ of toric IOLs in general, with the relative percentage of Tecnis ${ }^{\circledR}$ Toric IOLs significantly higher than AcrySof ${ }^{\circledR}$ Toric IOLs. Both of these had higher rates than the Staar ${ }^{\circledR}$ Toric and Trulign ${ }^{\circledR}$ Toric lenses, with the availability of higher Tecnis and AcrySof cylinder powers a likely contributing factor. The AcrySof Toric IOL appears to be less likely than the Tecnis Toric IOL to cause residual astigmatism as a result of misorientation. The Tecnis Toric IOL appears more likely to be misoriented in a counterclockwise direction; no such bias was observed with the AcrySof Toric, the Trulign ${ }^{\circledR}$ Toric, or the Staar Toric IOLs.

Keywords: rotation, AcrySof, Tecnis, toric back-calculator, cylinder

\section{Introduction}

Significant corneal astigmatism is present in a large proportion of patients presenting for cataract surgery; in a large data set, more than $36 \%$ of eyes had $>1.0 \mathrm{D}$ while an estimated $74 \%$ had $>0.50 \mathrm{D} .{ }^{1}$ One of the most effective ways to reduce astigmatism at the time of cataract surgery is by implanting toric intraocular lenses (IOLs). ${ }^{2}$ Results suggest $\sim 70 \%$ of eyes treated with toric IOLs will have a residual refractive astigmatism $\leq 0.5 \mathrm{D}$, though outcomes by study vary. ${ }^{3-5}$

One of the key factors influencing the amount of residual astigmatism in the eye is the orientation of the toric IOL. For every degree that the orientation of a toric lens differs from the ideal, there is an $\sim 3.3 \%$ decrease in its effectiveness at reducing astigmatism. ${ }^{6}$ If a toric lens is $30^{\circ}$ away from its ideal orientation, the magnitude of the preexisting astigmatism of the eye is not changed, but the axis of that astigmatism 
is altered. Such deviations from the intended lens location may be due to inaccuracies in the lens placement or a result of lens rotation. ${ }^{7}$

Lens rotation is one of the most commonly discussed reasons for toric IOL alignment errors. The average toric lens rotation is usually $<5^{\circ}$ with good rotational stability between visits..$^{2,7,8}$ Toric lens rotation more than $10^{\circ}$ is relatively rare, reported to vary from $3 \%$ to $20 \%$ depending on the IOL model. ${ }^{4}$ Low powered toric IOLs rotating $<10^{\circ}$ are expected to change most clinical refractions by $0.5 \mathrm{D}$ or less. ${ }^{6}$ Studies suggest that most toric lenses rotate within the first 14 days after surgery though rotation stability has been noted to take up to 1 month. $^{8-10}$

A toric back-calculation website (astigmatismfix.com, Ocular Surgical Data LLC, Sioux Falls, SD, USA) provides the opportunity for surgeons faced with residual astigmatism after a toric IOL implantation to enter current refractive and lens orientation data, along with the IOL cylinder power, to determine if reorienting the lens would reduce or eliminate the residual astigmatism. De-identified data related to the calculation are collected and stored in a file designed for analysis. Figure 1 shows the current data input screen (A) and the output screen (B) for the website.
This analysis was initiated to determine if the aggregate results from users of the toric back-calculation website could provide some insights into the nature of lens misorientation or rotation after implantation of toric IOLs.

\section{Methods}

An application to request approval for a review of the data collected from the website was submitted to the University of Iowa Human Subjects Office/Institutional Review Board. In the application, it was noted that there was no protected health information in the data set. On review, the Institutional Review Board indicated that approval for the proposed analysis was not required; a signed waiver was issued.

The complete data set from the website included all calculations collected since inception (January 1, 2012 to December 31, 2015). Earlier iterations of the data set, before September 2013, did not include lens identification or orientation data - records prior to September 2013 were excluded from the present analysis. A filtering process was applied to identify and remove erroneous data, and to account for multiple calculations for the same eye. Only records that included a lens identifier and the originally intended orientation of the IOL were retained. Data analysis included the

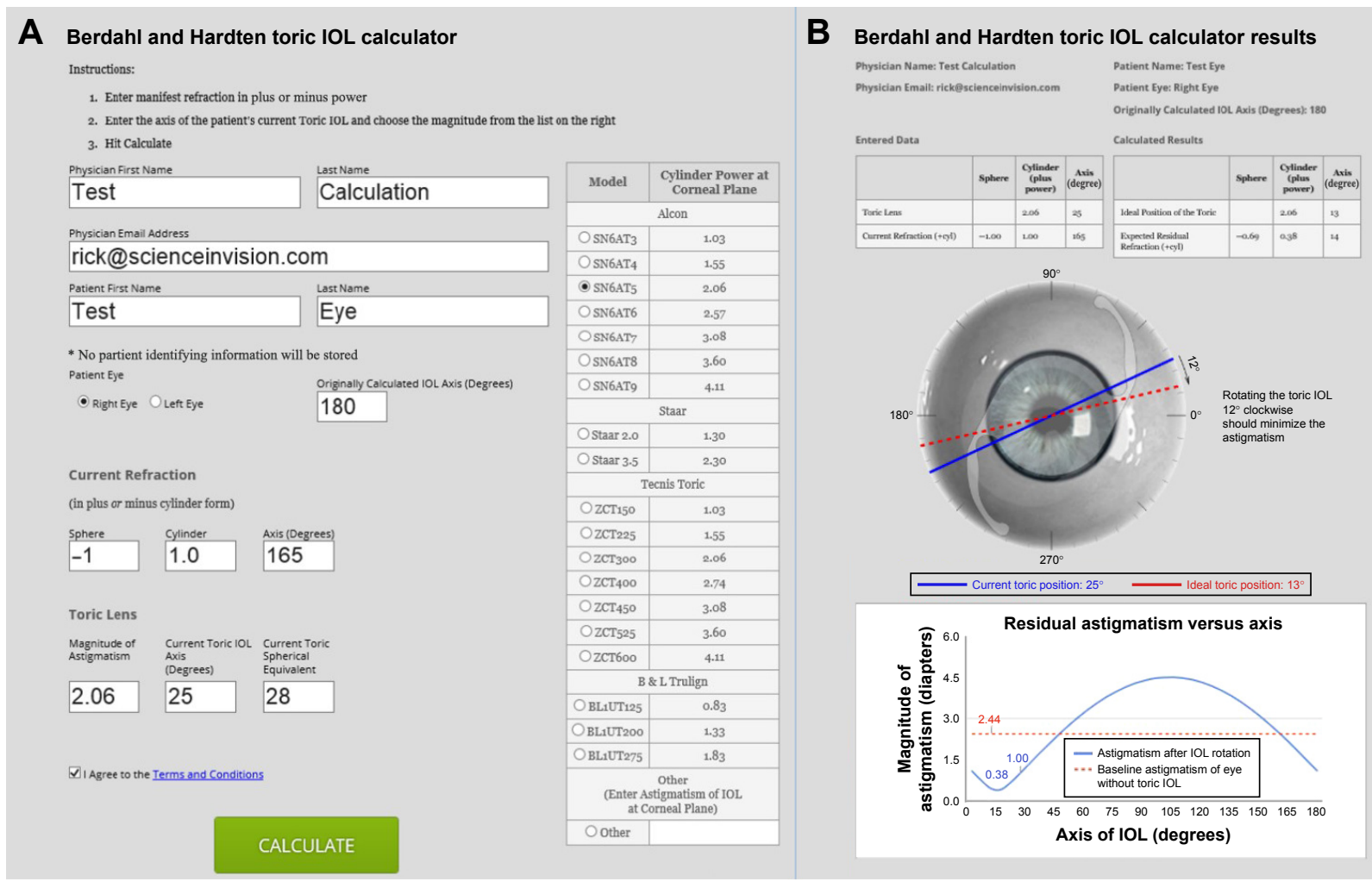

Figure I The astigmatismfix.com input (A) and output (B) screens.

Note: Copyright (C) 2015, reproduced with permission from Ocular Surgical Data LLC. ${ }^{16}$

Abbreviation: IOL, intraocular lens. 
generation of relevant numeric and categorical variables from the data set, such as the difference between the actual lens orientation and intended lens orientation. All astigmatism calculations were performed using double-angle vector math.

The potential success of reorientation in reducing residual refractive astigmatism was calculated in two ways. The first was the expected percentage reduction in the magnitude of residual astigmatism after optimal orientation of the IOL. The second was categorical, where a resultant magnitude of residual refractive astigmatism after reorientation that was $\leq 0.5 \mathrm{D}$ was considered a "Good" result; anything higher suggested an IOL with a different cylinder power would be required - "New IOL".

The data from the online website, stored in a commadelimited text file, were imported into an MS Access database (Microsoft Corporation, Redmond, WA, USA) for data checking, filtering, collation, and preliminary analysis. Statistical analyses were performed using the STATISTICA data analysis software system, version 12 (StatSoft, Inc., Tulsa, OK, USA). Statistical testing was performed using analysis of variance on continuous variables and appropriate nonparametric tests on categorical data. Statistical significance was set at $P=0.05$.

\section{Results}

The data file from inception of the website to December 31, 2015 included a total of 35,846 calculation records, with calculation requests submitted from an estimated 3,000 surgeons. Initial filters to identify valid records were applied (eg, "eye" = right or left, axes of astigmatism were between $0^{\circ}$ and $180^{\circ}$, absolute residual refractive cylinder $\leq 10.0 \mathrm{D}$, absolute residual refractive sphere was $\leq 6.0 \mathrm{D}$ ). Records from known site testers were also removed, along with records that were exact duplicates. Suspected research work ( $>10$ calculations on a given day for the same lens) was identified and related records deleted; users were queried using their email address to confirm such use. This preliminary data qualification reduced the data set to 19,018 calculation records. Of these, 8,793 were identified as "unique", being the only calculation on a given day for a specific IOL and a given user; the other 10,225 records were considered possible duplicates. A test of several algorithms to aggregate these possible duplicates suggested that the most reliable method was to take the final calculation record for a given user and IOL combination on a given day as the "best"; the other calculations were discarded. This approach yielded 4,019 records for a total of $12,812(8,793+4,019)$ calculation records for analysis.
Data from early versions of the software (before 9/13) were excluded, leaving 10,176 records that included the intended axis of orientation of the lens and identified the lens (by brand, or as "Not Specified/Other"). Of these, 8,229 records specifically identified the IOL; these records comprised the analytical data set for this particular analysis. There were four different toric IOLs specifically identified in the data set, catalogued as follows: group A (AcrySof ${ }^{\circledR}$ Toric, Alcon Laboratories, Inc, Fort Worth, TX, USA), group T (Tecnis $^{\circledR}$ Toric, Abbott Medical Optics Inc., Santa Ana, CA, USA), group S (Staar ${ }^{\circledR}$ Toric, Staar Surgical Company, Monrovia, CA, USA), and group B (Trulign ${ }^{\circledR}$ Toric, Bausch \& Lomb Surgical, Inc., Rancho Cucamonga, USA).

The time period in which the calculations above were made was from September 2013 to the end of 2015 . Figure 2 shows the percentage of toric back-calculations requested by group by quarter for 2014 and 2015, based on the estimated lens usage data for each quarter. ${ }^{11}$ Average quarterly lens usage volume in the USA in that 2-year period was 54,000 for group A, 12,000 for group T, 4,000 for group B, and 3,000 for group S. Back-calculation percentages are lower, and appear more variable, in the lower volume groups (B and S) over the given time period. Group T lenses were associated with a relatively higher usage of the toric back-calculator.

With the data set described above, the difference between the current (actual) lens orientation and the intended orientation could be calculated. Differences $>5^{\circ}$ were of interest, as orientation differences $<5^{\circ}$ were considered inside the noise of orientation measurement. Table 1 contains a summary of the number of lenses in the data record that were more than $5^{\circ}$ from intended orientation (in either direction) by lens group, along with the total number of lenses by lens group and estimated usage of lenses in the US in the time period of interest, as an indicator of relative volume. Comparing the two largest groups (groups A and T), a statistically significant difference was observed in both the percentage of lenses in the back-calculation data set that demonstrated an orientation different from intended and the percentage of lenses demonstrating an orientation difference relative to overall estimated lens use. The lenses in group $\mathrm{T}$ were significantly more likely to be misoriented relative to the lenses in group $\mathrm{A}$ $(P<0.01)$. Both groups $\mathrm{T}$ and $\mathrm{A}$ were significantly more likely to be misoriented than groups $\mathrm{B}$ and $\mathrm{S}(P<0.01)$ with no difference between groups $\mathrm{B}$ and $\mathrm{S}(P=0.90)$.

Direction of orientation was also of interest; this could be determined from the sign of the angle difference between the intended and actual orientation, as it was presumed that lenses rotated or were misaligned by $<90^{\circ}$. Figure 3 shows 


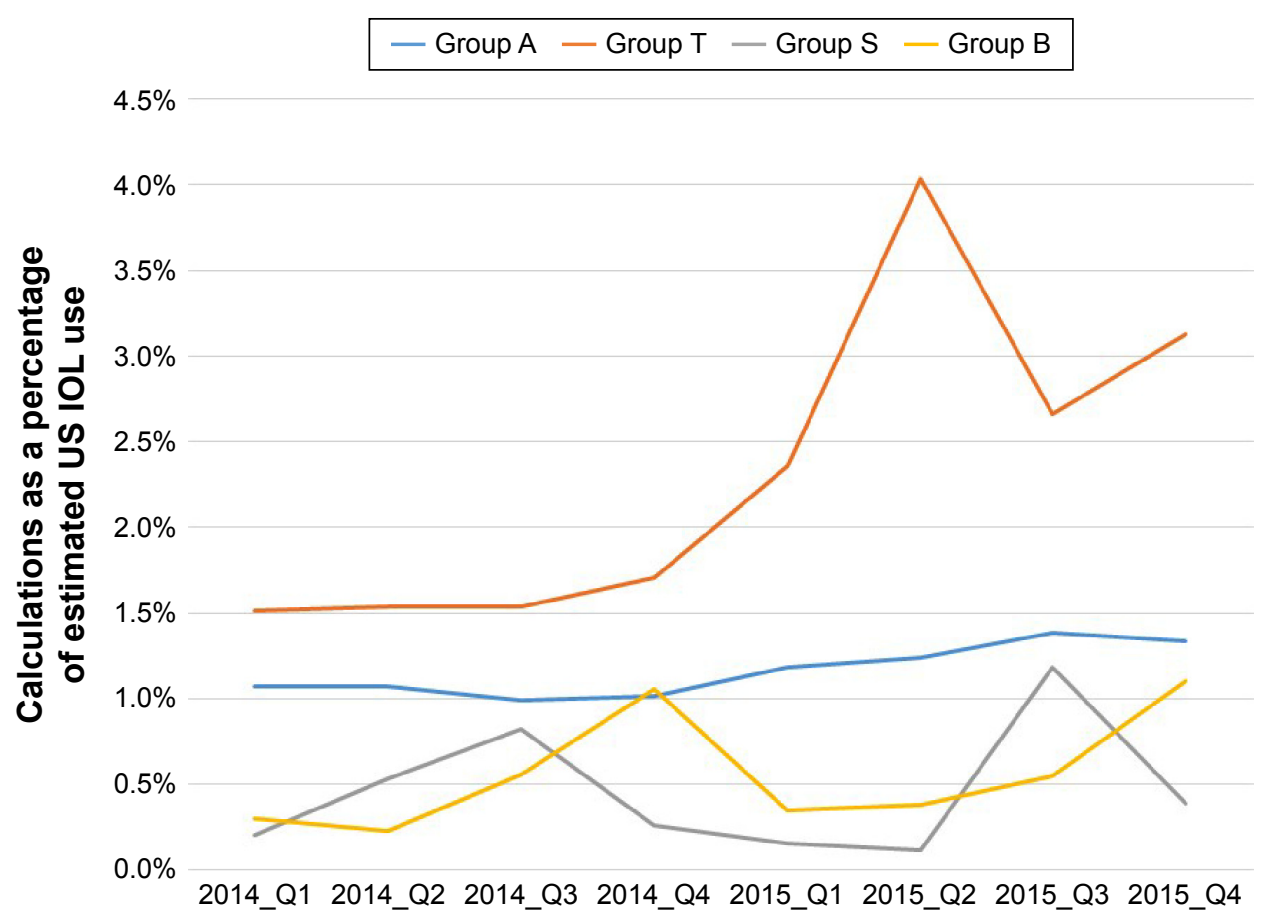

Figure 2 Online toric back-calculations as a percentage of estimated lens usage in the USA by group.

Notes: Group A, AcrySof ${ }^{\circledR}$ Toric (Alcon Laboratories, Inc, Fort Worth, TX, USA); group T, Tecnis ${ }^{\circledR}$ Toric (Abbott Medical Optics Inc., Santa Ana, CA, USA); group S, Staar ${ }^{\circledR}$ Toric (Staar Surgical Company, Monrovia, CA, USA); and group B, Trulign ${ }^{\circledR}$ Toric (Bausch \& Lomb Surgical, Inc., Rancho Cucamonga, USA).

Abbreviations: IOL, intraocular lens; QI, January I to March 3I; Q2, April I to June 30; Q3, July I to September 30; Q4, October I to December 3I.

the percentage of eyes by IOL group that were clockwise and counterclockwise of the intended orientation. Only group $\mathrm{T}$ demonstrated any statistically significant bias, with a higher percentage of lenses oriented counterclockwise from the intended direction $(P<0.001$, chi-square test, $95 \%$ confidence interval of the odds ratio $[1.65,2.13])$.

The average refractive cylinder before any calculated lens adjustment was 1.8 \pm 1.0 D. Figure 4 shows the expected percentage reduction in the magnitude of residual refractive astigmatism by IOL group and whether the IOL was oriented as intended or not. There was a significantly higher reduction expected for lenses that were not oriented as intended, relative to those that were oriented as intended, for all lens groups but group B. A slightly higher reduction was expected for group $\mathrm{T}$ than A with lenses that were not oriented as intended $(P<0.001)$.

Table 2 contains a summary of the categorical findings, indicating whether a new lens might be the best option (residual refractive cylinder $>0.5 \mathrm{D}$ ) after consideration of reorienting the lens in the eye. Where the IOL was oriented within $5^{\circ}$ of the intended orientation, only the group B lenses differed in the percentage of new IOLs suggested $(P>0.05)$ between the lens groups, with a higher percentage of Good results. Where IOLs were not within $5^{\circ}$ of the intended orientation, there was a significantly lower percentage of Good results for group A, and a significantly higher percentage of Good results for group T, with no difference between the other groups. Overall, calculations suggested

Table I Percentage of intraocular lenses not oriented as intended

\begin{tabular}{|c|c|c|c|c|c|c|c|}
\hline Group & $\begin{array}{l}\text { Orientation } \geq 5^{\circ} \\
\text { from intended }(n)\end{array}$ & $\begin{array}{l}\text { Total } \\
\text { cases }\end{array}$ & $\begin{array}{l}\% \text { of total } \\
\text { cases }\end{array}$ & $P,{ }^{a} \mathbf{O R}^{\mathrm{b}}$ & $\begin{array}{l}\text { Estimated } \\
\text { usage }^{c}\end{array}$ & $\begin{array}{l}\% \text { of estimated } \\
\text { usage }\end{array}$ & $P,{ }^{\mathrm{a}} \mathbf{O} \mathbf{R}^{\mathrm{b}}$ \\
\hline Group A & 3,556 & 5,552 & 64 & $<0.0001$ & 473,400 & 0.75 & $<0.0001$ \\
\hline Group T & 1,953 & 2,406 & 81 & $(2.15,2.72)$ & 105,000 & 1.86 & $(2.37,2.65$ \\
\hline Group B & 98 & 177 & 55 & & 34,100 & 0.29 & \\
\hline Group S & 67 & 94 & 71 & & 23,800 & 0.28 & \\
\hline Total & 5,674 & 8,229 & 69 & & 636,300 & 0.89 & \\
\hline
\end{tabular}

Notes: a Chi-square test, ${ }^{b} 95 \%$ confidence limit of odds ratio (OR), cbased on Market Scope quarterly survey of US cataract surgeons. Group A, AcrySof ${ }^{\circledR}$ Toric (Alcon Laboratories, Inc, Fort Worth, TX, USA); group T, Tecnis ${ }^{\circledast}$ Toric (Abbott Medical Optics Inc., Santa Ana, CA, USA); group S, Staar ${ }^{\circledast}$ Toric (Staar Surgical Company, Monrovia, CA, USA); and group B, Trulign ${ }^{\circledast}$ Toric (Bausch \& Lomb Surgical, Inc., Rancho Cucamonga, USA). 


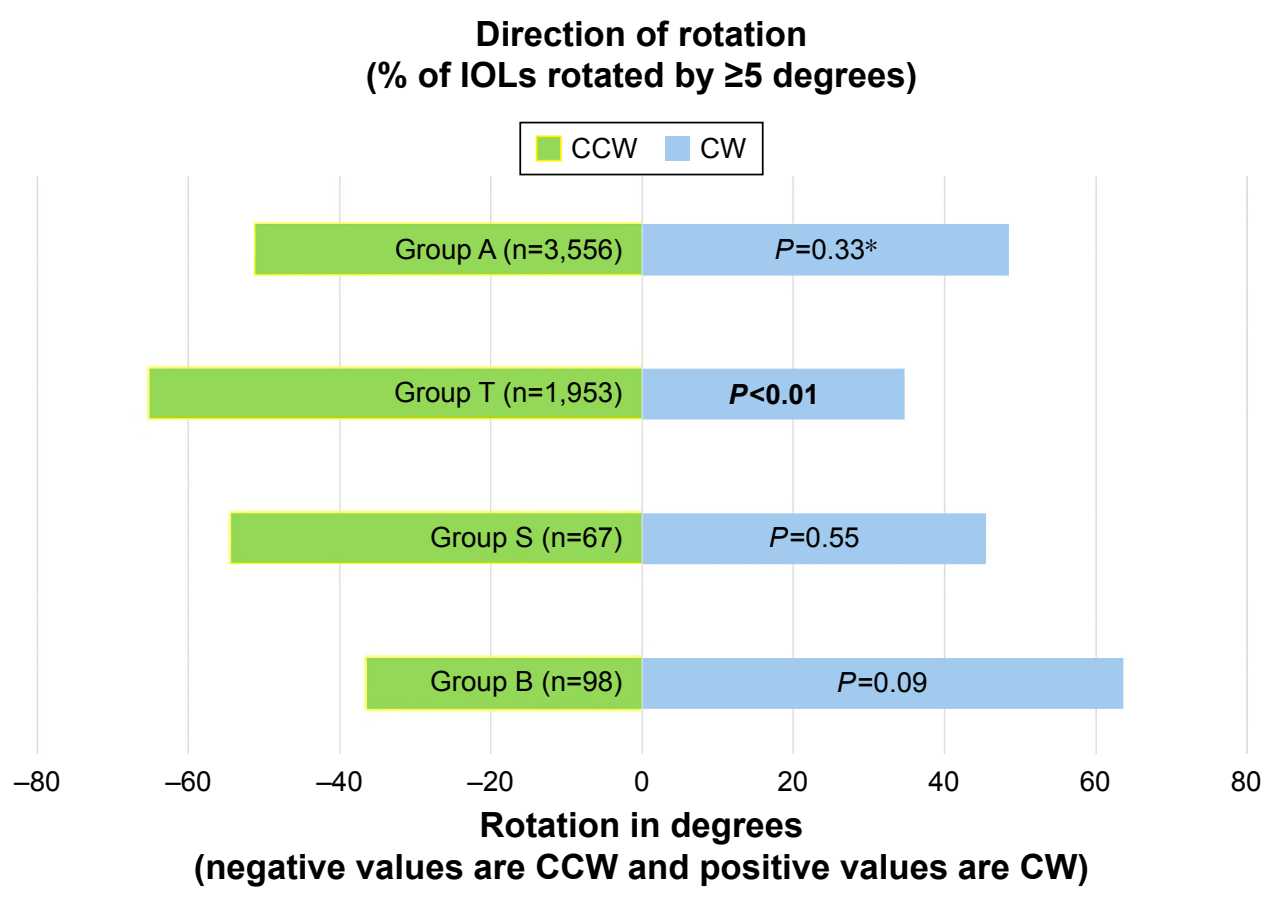

Figure 3 Lens misorientation by group and direction.

Notes: *Likelihood results are equally distributed around zero. Group A, AcrySof ${ }^{\circledR}$ Toric (Alcon Laboratories, Inc, Fort Worth, TX, USA); group T, Tecnis ${ }^{\circledR}$ Toric (Abbott Medical Optics Inc., Santa Ana, CA, USA); group S, Staar ${ }^{\circledR}$ Toric (Staar Surgical Company, Monrovia, CA, USA); and group B, Trulign ${ }^{\circledR}$ Toric (Bausch \& Lomb Surgical, Inc., Rancho Cucamonga, USA). Statistically significant values are shown in bold $(P<0.05)$.

Abbreviations: CCW, counterclockwise; CW, clockwise; IOL, intraocular lens.

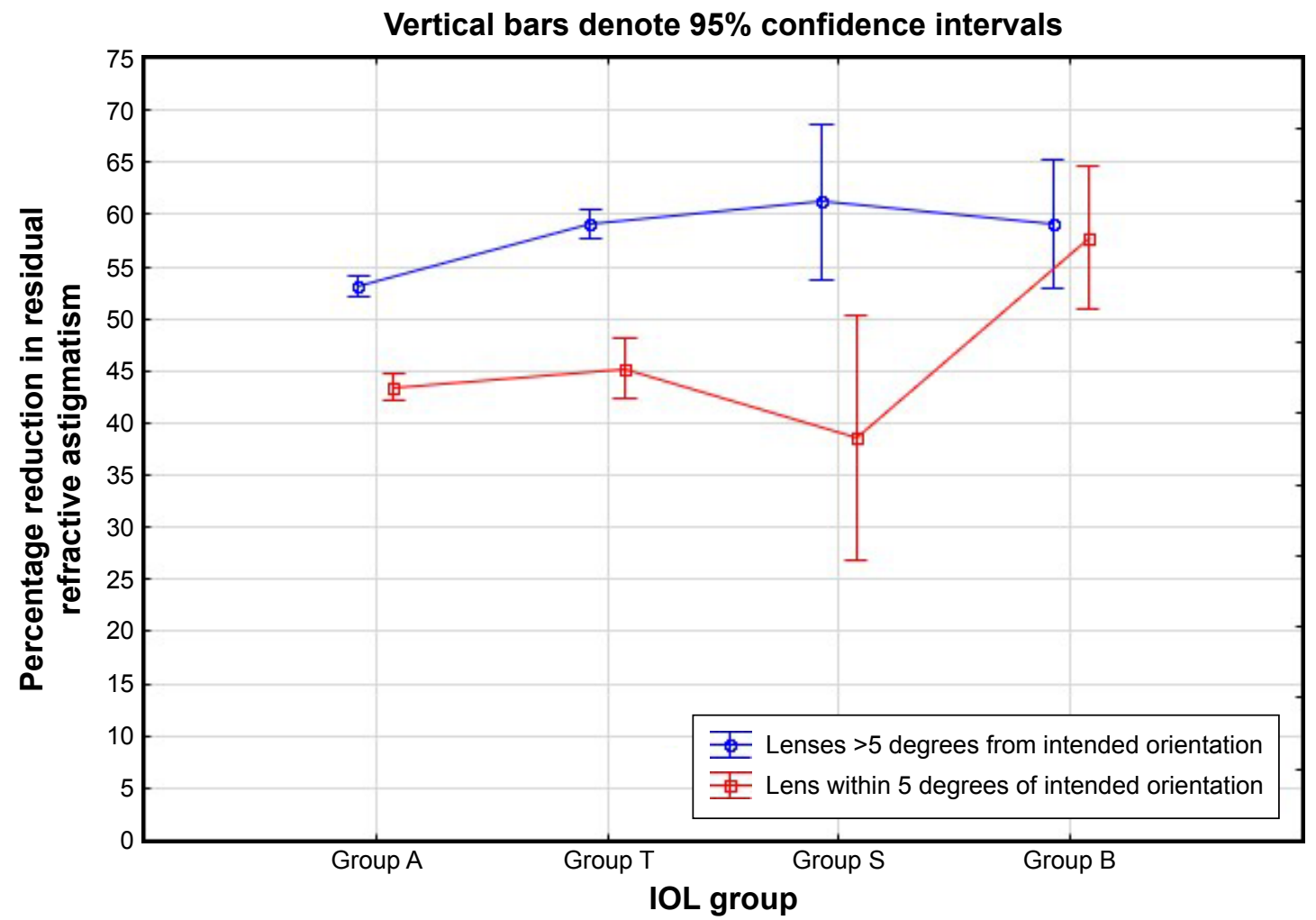

Figure 4 Expected percentage reduction in residual refractive astigmatism magnitude after IOL reorientation.

Notes: Group A, AcrySof ${ }^{\circledR}$ Toric (Alcon Laboratories, Inc, Fort Worth, TX, USA); group T, Tecnis ${ }^{\circledR}$ Toric (Abbott Medical Optics Inc., Santa Ana, CA, USA); group S, Staar ${ }^{\circledR}$ Toric (Staar Surgical Company, Monrovia, CA, USA); and group B, Trulign ${ }^{\circledR}$ Toric (Bausch \& Lomb Surgical, Inc., Rancho Cucamonga, USA).

Abbreviation: IOL, intraocular lens. 
Table 2 Suggested new intraocular lens (IOL) by lens group and orientation

\begin{tabular}{lllllll}
\hline $\begin{array}{l}\text { Oriented } \\
\text { as intended }\end{array}$ & $\begin{array}{l}\text { IOL } \\
\text { group }\end{array}$ & Total & Good $^{\mathrm{a}}$ & $\begin{array}{l}\text { New } \\
\text { IOL }\end{array}$ & \% good & $P$-value \\
\hline No & Group A & 3,556 & 1,382 & 2,174 & 38.9 & $<0.01$ \\
No & Group T & I,953 & 928 & I,025 & 47.5 & $<0.01$ \\
No & Group B & 98 & 52 & 46 & 53.1 & 0.12 \\
No & Group S & 67 & 29 & 38 & 43.3 & 0.86 \\
No & All lenses & 5,674 & 2,391 & 3,283 & 42.1 & \\
Yes & Group A & 1,996 & 671 & 1,325 & 33.6 & 0.59 \\
Yes & Group T & 453 & 160 & 293 & 35.3 & 0.78 \\
Yes & Group B & 79 & 41 & 38 & 51.9 & 0.03 \\
Yes & Group S & 27 & 7 & 20 & 25.9 & 0.55 \\
Yes & Overall & 2,555 & 879 & 1,676 & 34.4 & \\
All lenses & & 8,229 & 3,270 & 4,959 & 39.7 & \\
\hline
\end{tabular}

Notes: ${ }^{a}$ Expected residual refractive cylinder $\leq 0.50 \mathrm{D}$ after optimal IOL rotation, bexpected residual refractive cylinder $>0.5 \mathrm{D}$ after optimal IOL rotation, 'chi-square test of expected vs observed ratio. Group A, AcrySof ${ }^{\circledR}$ Toric (Alcon Laboratories, Inc, Fort Worth, TX, USA); group T, Tecnis ${ }^{\circledR}$ Toric (Abbott Medical Optics Inc., Santa Ana, CA, USA); group S, Staar ${ }^{\circledR}$ Toric (Staar Surgical Company, Monrovia, CA, USA); and group B, Trulign ${ }^{\circledR}$ Toric (Bausch \& Lomb Surgical, Inc., Rancho Cucamonga, USA).

that residual refractive astigmatism magnitude could be reduced to below $0.5 \mathrm{D}$ in $\sim 40 \%$ of all cases, with a higher rate $(42 \%)$ in eyes with a lens not at the intended orientation and a lower rate $(34 \%)$ in eyes with a lens within $5^{\circ}$ of the intended orientation.

\section{Discussion}

A number of factors have been identified that appear to increase the likelihood of toric IOL rotation. These include longer axial lengths, ${ }^{10}$ inaccurate capsulorhexis size and centration, ${ }^{8}$ incomplete removal of ophthalmic viscosurgical devices, ${ }^{8,12}$ changes in intraocular pressure, ${ }^{12}$ and orientation of the IOL. Additional factors include the planned IOL orientation, as well as changes in the patient's intraocular pressure. ${ }^{12}$ Some of these factors are correlated. Patients with long eyes are likely to have more corneal measurement errors, inaccuracies in the capsulorhexis size, receive a thinner lens, and may already have weak zonules, all of which can contribute to poor lens stability. ${ }^{8,10,13}$ In one large study, 1.6\% (6/378) of eyes exhibited more than $20^{\circ}$ of toric lens rotation; all six eyes had an axial length $>25.0 \mathrm{~mm}$ and a vertically-oriented lens. ${ }^{8}$ Lower levels of anterior capsular opacification are also associated with an increased likelihood of lens rotation because of the reduced binding force from the anterior capsule to the lens. ${ }^{13}$ Finally, lens material and design have also been reported to affect rotational stability. ${ }^{8,12}$ Our results, with significantly more misoriented lenses for one specific brand of toric IOL, provide additional evidence for this contention.
The "rate" of significant misorientation was calculated here as the number of cases submitted for back-calculation over estimated US lens usage in the same time period. The rate of just under $1 \%$ reported here appears reasonably consistent with previous findings. In a recent meta-analysis, toric IOLs in $1.1 \%(6 / 554)$ of eyes needed to be reoriented due to excessive rotation, though one of the lenses with excessive rotation was of a design no longer commercially available. ${ }^{2}$ It should be noted that a significant number of cases where residual astigmatism is present following a toric IOL implantation may not have been entered into astigmatismfix.com. However, relative rates reported here are likely to be valid because, even though possible, it is not expected that users of a specific IOL would be more or less likely to utilize astigmatismfix.com for calculations than users of another IOL. Our results suggest that residual astigmatism as a function of misorientation was more likely with the Tecnis toric lens than the AcrySof toric lens, but rates for both lenses are very low $(<2 \%)$ in our data set. Smaller data sets of normative data have not shown this difference, which is likely a function of the smaller sample size. ${ }^{14}$

Figure 2 shows lower rates of misorientation for two lens models (Trulign ${ }^{\circledR}$ Toric and Staar Toric). The maximum cylinder power at the corneal plane is $<2.50 \mathrm{D}$ for both of these IOLs. All other things being equal, lower cylinder power IOLs will induce relatively lower residual refractive astigmatism with misorientation; it is reasonable to surmise that this would result in correspondingly fewer toric back-calculations being submitted, given that the average residual refractive cylinder for all calculations analyzed here was 1.8 D. Figure 2 also shows an apparent increase in the rate of back-calculations for the Tecnis Toric lens around the beginning of 2015. This may be a function of higher cylinder power options that became available for this IOL in 2015. The effects of the level of cylinder in these IOLs have not been analyzed here; we anticipate addressing this issue in a future manuscript.

The direction of toric lens rotation has been reported to occur most often in a clockwise direction. ${ }^{10}$ This is usually attributed to the configuration of the lens haptics and/or capsule effects. ${ }^{8}, 15$ Our findings suggest no bias in lens misorientation with three of four toric IOLs in our data set, but a significant bias to counterclockwise misorientation with the Tecnis Toric IOL. There are insufficient data in the current calculation record to determine whether differences in orientation were due to misalignment or actual IOL rotation. Future modifications to the website may allow collection of more detailed data, which might help with this (and other) question. 
A limitation of the study is that the analysis above was primarily concerned with a difference in lens orientation from intended, as this is a measure of the ability to accurately place the lens and have the lens remain in place. It should be noted that the intended toric lens orientation, determined from preoperative calculations, may not be the ideal orientation. There were significant numbers of lenses of all brands that were oriented as intended, yet significant residual refractive astigmatism is evident. While it has been suggested that inaccuracies in the corneal measurements are a major cause of refractive surprises, ${ }^{7}$ particularly for those with little preoperative astigmatism, the issue has not been investigated here. Other possibilities include the effects of surgically induced astigmatism, posterior corneal astigmatism, and variability in refractive astigmatism measurement. Again, modifications to the website may provide the additional data necessary to explore these issues further.

Finally, the website was designed not for the purpose of data collection, but to provide surgeons a method to determine if residual refractive astigmatism after toric IOL implantation might be reduced or eliminated. The average reduction in refractive cylinder expected after IOL rotation was $\sim 50 \%$, as shown in Figure 4. The calculated results shown in Table 2 suggest that IOL rotation, without exchange, will be sufficient to reduce residual refractive astigmatism to below $0.50 \mathrm{D}$ in more than $40 \%$ of cases. For the remaining $60 \%$ of cases, an alternative method of correction, such as IOL exchange or laser vision correction, might be required to achieve sufficient reduction of residual astigmatism.

\section{Conclusion}

The percentage of eyes with lens orientation $\geq 5^{\circ}$ from intended in the Toric Results Analyzer data set was $<1 \%$ of toric IOLs in general, with the relative percentage of Tecnis Toric IOLs significantly higher than AcrySof Toric IOLs. The AcrySof Toric IOL appears to be less likely than the Tecnis Toric IOL to cause residual astigmatism as a result of misorientation. The Tecnis Toric IOL appears more likely to be misoriented in a counterclockwise direction; no such bias was observed with the AcrySof Toric IOL.

\section{Acknowledgments}

Data analysis and the preparation of this manuscript were supported with an investigator-initiated research grant to Ocular Surgical Data, LLC (OSD) from Alcon (Fort Worth, TX, USA). OSD provided funding to Science in Vision to assist with data analysis and preparation of this manuscript.
Sarah Y Makari, OD, a consultant to Science in Vision, received compensation for providing writing assistance to the authors in preparation of the manuscript.

\section{Disclosure}

Drs Berdahl and Hardten are owners of OSD, makers of astigmatismfix.com. Dr Berdahl is a consultant to Alcon, AMO, and Bausch \& Lomb. Dr Hardten is a consultant to AMO, ESI, and TLC Vision. Dr Potvin is a consultant to Alcon, Haag-Streit, and Oculus Gmbh. The authors report no other conflicts of interest in this work.

\section{References}

1. Hoffmann PC, Hütz WW. Analysis of biometry and prevalence data for corneal astigmatism in 23,239 eyes. J Cataract Refract Surg. 2010; 36(9):1479-1485.

2. Kessel L, Andresen J, Tendal B, Erngaard D, Flesner P, Hjortdal J. Toric intraocular lenses in the correction of astigmatism during cataract surgery: a systematic review and meta-analysis. Ophthalmology. 2016; 123(2):275-286.

3. Ahmed II, Rocha G, Slomovic AR, et al; for Canadian Toric Study Group. Visual function and patient experience after bilateral implantation of toric intraocular lenses. J Cataract Refract Surg. 2010;36(4): 609-616.

4. Visser N, Bauer NJ, Nuijts RM. Toric intraocular lenses: historical overview, patient selection, IOL calculation, surgical techniques, clinical outcomes, and complications. J Cataract Refract Surg. 2013; 39(4):624-637.

5. Agresta B, Knorz MC, Donatti C, Jackson D. Visual acuity improvements after implantation of toric intraocular lenses in cataract patients with astigmatism: a systematic review. BMC Ophthalmol [serial on the Internet] 2012 August [cited 2016 May 26];12:[about 6 p.]. Available from: http://www.biomedcentral.com/1471-2415/12/41. Accessed May 31, 2016.

6. Felipe A, Artigas JM, Díez-Ajenjo A, García-Domene C, Alcocer P. Residual astigmatism produced by toric intraocular lens rotation. J Cataract Refract Surg. 2011;37(10):1895-1901.

7. Hirnschall N, Hoffmann PC, Draschl P, Maedel S, Findl O. Evaluation of factors influencing the remaining astigmatism after toric intraocular lens implantation. J Refract Surg. 2014;30(6):394-400.

8. Miyake T, Kamiya K, Amano R, Iida Y, Tsunehiro S, Shimizu K. Longterm clinical outcomes of toric intraocular lens implantation in cataract cases with preexisting astigmatism. J Cataract Refract Surg. 2014; 40(10):1654-1660.

9. Jampaulo M, Olson MD, Miller KM. Long-term Staar toric intraocular lens rotational stability. Am J Ophthalmol. 2008;146(4):550-553.

10. Shah GD, Praveen MR, Vasavada AR, Vasavada VA, Rampal G, Shastry LR. Rotational stability of a toric intraocular lens: influence of axial length and alignment in the capsular bag. J Cataract Refract Surg. 2012;38(1):54-59.

11. Toric IOL use reported in the quarterly survey of US cataract surgeons. Saint Louis, MO: Market Scope, LLC.

12. Emesz M, Dexl AK, Krall EM, et al. Randomized controlled clinical trial to evaluate different intraocular lenses for the surgical compensation of low to moderate-to-high regular corneal astigmatism during cataract surgery. J Cataract Refract Surg. 2015;41(12): 2683-2694.

13. Zhu X, He W, Zhang K, Lu Y. Factors influencing 1-year rotational stability of AcrySof Toric intraocular lenses. Br J Ophthalmol. 2016; 100(2):263-268. 
14. Ferreira TB, Almeida A. Comparison of the visual outcomes and OPDscan results of AMO Tecnis toric and Alcon Acrysof IQ toric intraocular lenses. J Refract Surg. 2012;28(8):551-555.

15. Hirnschall N, Maedel S, Weber M, Findl O. Rotational stability of a single-piece toric acrylic intraocular lens: a pilot study. Am J Ophthalmol. 2014;157(2):405-411.
16. Toric Results Analyzer. Berdahl \& Hardten Toric IOL Calculator. Available from: http://astigmatismfix.com/. Accessed September 9, 2016.

\section{Publish your work in this journal}

Clinical Ophthalmology is an international, peer-reviewed journal covering all subspecialties within ophthalmology. Key topics include: Optometry; Visual science; Pharmacology and drug therapy in eye diseases; Basic Sciences; Primary and Secondary eye care; Patient Safety and Quality of Care Improvements. This journal is indexed on

\section{Dovepress}

PubMed Central and CAS, and is the official journal of The Society of Clinical Ophthalmology (SCO). The manuscript management system is completely online and includes a very quick and fair peer-review system, which is all easy to use. Visit http://www.dovepress.com/ testimonials.php to read real quotes from published authors. 